\title{
Millions flock to new US health insurance markets
}

I t was unpopular with many Americans, plagued with setbacks and vilified by political opponents. But when the first big deadline drew near to sign up for health coverage under the Affordable Care Act, there was a huge last-minute clamour to get it before it's gone for the year.

Ultimately, more than seven million people gained coverage in the 2014 enrolment season in insurance marketplaces established by President Barack Obama's health care law. The deadline passed Mar. 31, with a grace period into April for those who started applications in time.

It was a frustrating and at times impossible journey through a buggy website, but Obama met his enrolment target and millions came away with health coverage, some for the first time. Four in five who enrolled in the new private markets, called exchanges, qualified for federal subsidies that reduced their premiums.

In central Florida, Colette Heid led a team of 14 "navigators" who helped 3500 families and individuals in Indian River and Brevard counties get coverage from the Affordable Care Act, widely known as Obamacare. "For someone who was previously uninsured and not able to go to the doctor for preventable care," she says, "it's been life-changing."

The rush to meet the deadline which resulted in clogged web portals, jammed phone lines and long lines at sign-up centres - doesn't mean everybody who signed up supports the new law. Those who go uninsured will be penalized when they file their 2014 taxes in early 2015.

Nor was the open enrolment season the only test for the health law. Most insured Americans get coverage from their employers, with whom they share the cost of premiums. Obamacare has not yet had to deal with that huge segment of the market, which is facing growing pressure to control costs.

The new exchanges are primarily for

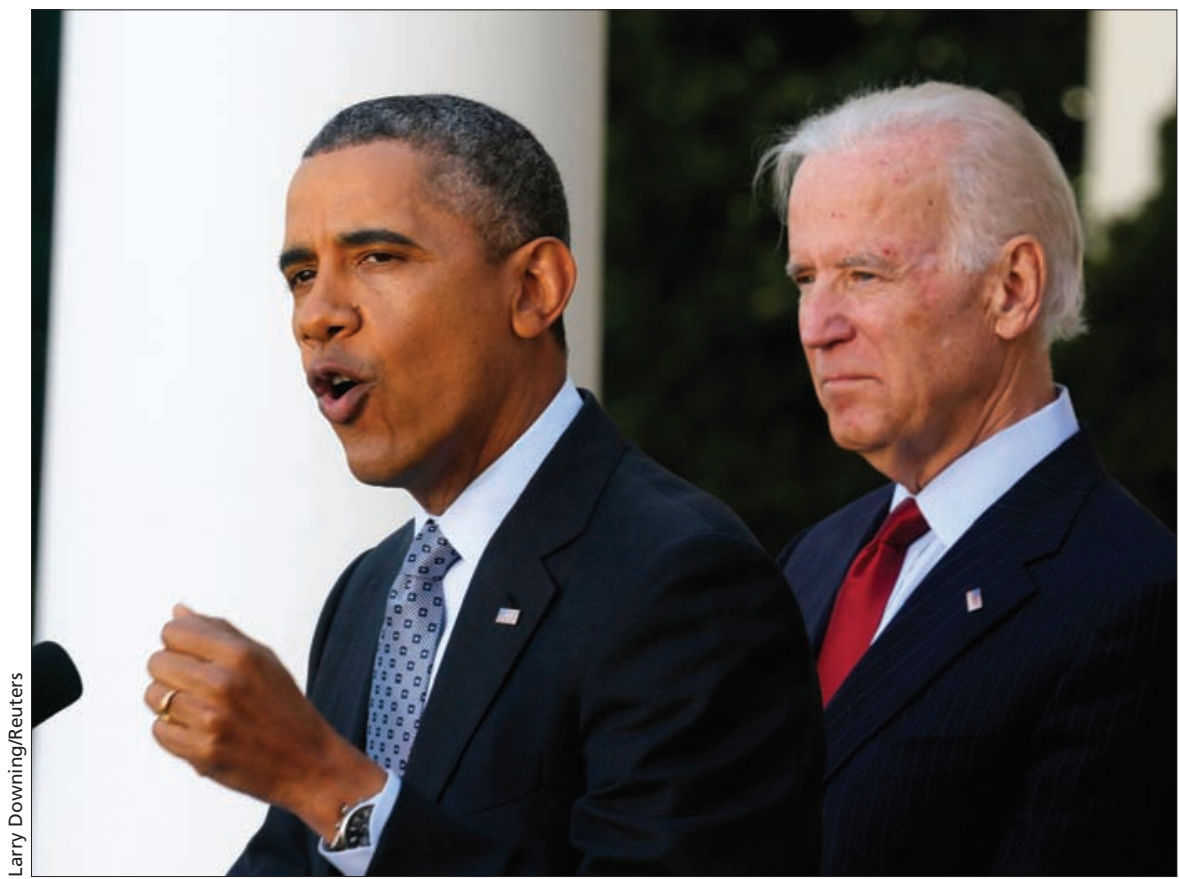

"Armageddon has not arrived," US President Barack Obama said in a speech about Obamacare. "Instead, this law is helping millions of Americans, and in the coming years it will help millions more."

people who don't get insurance on the job, like the self-employed or those who work for small companies. Each state has an exchange offering policies with varying premiums, deductibles and conditions.

The overarching standard is that no one can be denied coverage or charged exorbitant rates because of pre-existing illness. The patient needing an organ transplant gets the same access to insurance as someone who is the picture of health.

But Jenifer Duncan of Anderson, Indiana, found nothing for her when she checked HealthCare.gov for an exchange policy. Self-employed and making about $\$ 14000$ a year, with a jobless husband, she found monthly premiums of \$250-\$450 with deductibles as high as $\$ 3500$. "We can't afford that; otherwise we wouldn't be living with our inlaws right now," she says.

In Angelica, New York, though, sweet-shop owner Karen Ash found far cheaper and better insurance on the exchange than she and her husband had before. She also helped her parttime employee, previously uninsured and with a chronic medical condition, find a plan costing less than $\$ 50$ a month after subsidies.

"The obstructionists and haters have a more provocative story, to be sure," she says of Obamacare's critics. "But mine has a happy ending.'

Although 7.1 million got coverage in the exchanges, many switched from other insurers. As well, nearly five million people got cancellation notices months earlier because insurers pulled policies that didn't meet the higher demands of the health law. The percentage of uninsured adults did drop, though, from $17.1 \%$ in the fourth quarter of 2013 to $15.9 \%$ in 2014 , according to the Gallup-Healthways WellBeing Index.

Those who flocked to the exchanges in the first open enrolment season tended to be middle aged, older or sicker. The new system needs plenty 
of young and healthy people paying premiums to keep costs down. Worries persist that the next round of insurance rates in late fall will be higher and that employers will drop coverage and let workers fend for themselves in the exchanges.

Many Republicans remain sworn to repeal the law, an increasingly unrealistic goal but one that resonates with plenty of voters in the campaign for November elections that will determine which party controls Congress.

Obama swiped at his opponents in a White House Rose Garden event. "Armageddon has not arrived," he said.
"Instead, this law is helping millions of Americans, and in the coming years it will help millions more. ... As messy as it's been sometimes, as contentious as it's been sometimes, it is progress." - Cal Woodward, Washington, DC

CMAJ 2014. DOI:10.1503/cmaj.109-4778 